REGARDS

SUR LEECONOMIE ALLEMANDE

BULLETIN ECONOMIQUE DU CRAC

\section{Regards sur l'économie allemande}

Bulletin économique du CIRAC

$91 \mid 2009$

Varia

\title{
Histoire sociale
}

WEHLER Hans-Ulrich, Deutsche Gesellschaftsgeschichte. 1949-1990

\section{OpenEdition}

\section{Journals}

Édition électronique

URL : http://journals.openedition.org/rea/3721

DOI : $10.4000 /$ rea.3721

ISBN : 978-2-8218-0878-2

ISSN : 1965-0787

\section{Éditeur}

CIRAC

\section{Édition imprimée}

Date de publication : 1 mai 2009

ISSN : 1156-8992

Référence électronique

" Histoire sociale », Regards sur l'économie allemande [En ligne], 91 | mai 2009, mis en ligne le 20 mai 2009, consulté le 22 septembre 2020. URL : http://journals.openedition.org/rea/3721 ; DOI : https:// doi.org/10.4000/rea.3721

Ce document a été généré automatiquement le 22 septembre 2020

(C) CIRAC 


\section{Histoire sociale}

WEHLER Hans-Ulrich, Deutsche Gesellschaftsgeschichte. 1949-1990

\section{RÉFÉRENCE}

WEHLER Hans-Ulrich, Deutsche Gesellschaftsgeschichte. 1949-1990, C.H.Beck, Munich, 2008, 534 p.

1 Voilà le cinquième et dernier tome de l'œuvre monumentale de Wehler, professeur émérite d'histoire à l'Université de Bielefeld: une histoire de la société allemande de 1700 à nos jours. Le présent volume présente l'évolution en parallèle des deux Etats allemands depuis 1945, mais délibérément et ouvertement dans la perspective d'un Allemand de l'ouest. Le verdict qu'il rend sur l'inégalité sous le régime de la RDA est tout aussi sévère que sa description de l'ascenseur social ouest-allemand est nuancée. Mais ce qui fait la richesse de cet ouvrage, c'est que, mû par une approche transversale trop rare dans sa discipline (ce qu'il regrette expressément), l'auteur intègre dans son analyse "les conditions structurelles et les processus d'évolution de la culture »: à savoir l'évolution des Eglises, du système scolaire et universitaire, ainsi que du «marché médiatique et littéraire » (RFA) en opposition avec «la double expérience d'une dictature » (RDA). A lire. (ib) 